Article

\title{
A Facile and Simple Method for Preparation of Novel High-Efficient Form-Stable Phase Change Materials Using Biomimetic-Synthetic Polydopamine Microspheres as a Matrix for Thermal Energy Storage
}

\author{
Junkai Gao ${ }^{1}$, Xi Tang ${ }^{1}$, Zhengshou Chen ${ }^{2, *}$, Han Ding ${ }^{1}$, Yi Liu ${ }^{1}$, Xuebin Li ${ }^{1}$ and Yan Chen ${ }^{1, *}$ \\ 1 School of Port and Transportation Engineering, Zhejiang Ocean University, Zhoushan 316022, China; \\ gaojk@zjou.edu.cn (J.G.); 18858384935@163.com (X.T.); dinghan940519@163.com (H.D.); \\ ydb1629@163.com (Y.L.); 1xbsgdsg@163.com (X.L.) \\ 2 Department of Naval Architecture and Ocean Engineering, Zhejiang Ocean University, \\ Zhoushan 316022, China \\ * Correspondence: aaaczs@163.com (Z.C.); chenyan@zjou.edu.cn (Y.C.); Tel.: +86-580-2550034 (Z.C.); \\ $+86-580-2554491$ (Y.C.)
}

Received: 7 August 2019; Accepted: 11 September 2019; Published: 15 September 2019

\begin{abstract}
Polydopamine microspheres (PDAMs), synthesized using a biomimetic method, were used as a matrix for polyethylene glycol (PEG) to develop a novel high-efficient form-stable phase change material (PEG/PDAM) using a simple vacuum impregnation strategy. The PDAMs were first used as a support for the organic phase change materials, and the biomimetic synthesis of the PDAMs had the advantages of easy operation, mild conditions, and environmental friendliness. The characteristics and thermal properties of the PEG/PDAMs were investigated using SEM, FTIR, XRD, TGA, DSC, and XPS, and the results demonstrated that the PEG/PDAMs possessed favourable heat storage capacity, excellent thermal stability, and reliability, and the melting and freezing latent heats of PEG/PDAM-3 reached $133.20 \pm 2.50 \mathrm{~J} / \mathrm{g}$ and $107.55 \pm 4.45 \mathrm{~J} / \mathrm{g}$, respectively. Therefore, the PEG/PDAMs possess great potential in real-world applications for thermal energy storage. Additionally, the study on the interaction mechanism between the PEG and PDAMs indicated that PEG was immobilized on the surface of PDAMs through hydrogen bonds between the PEG molecules and the PDAMs. Moreover, the PDAMs can also be used as a matrix for other organic materials for the preparation of form-stable phase change materials.
\end{abstract}

Keywords: biomimetic synthesis; polydopamine microsphere; phase change material; polyethylene glycol; thermal energy storage

\section{Introduction}

Currently, human society is progressing rapidly on various fronts. Large amounts of energy and resources are needed to satisfy the requirements of social development; however, the majority of these inputs are limited and non-renewable. A serious waste of natural energy and the irrational use of resources have led to the grievous pollution of the environment. Therefore, significant attention has been paid to the development of new energy storage systems and their utilization by a number of researchers. Phase change materials (PCMs) are indispensable in methods and applications for energy conservation because they absorb and release a large amount of latent heat in the course of the phase change process [1-5].

Phase change materials have various merits, such as high energy density, cyclic utilization, excellent thermal stability, etc. [6], and therefore, PCMs can be used in various applications, such as in 
buildings, temperature-regulating fabrics, solar energy systems [7], electron device heat transfer [8], industrial waste heat utilization, and air conditioning systems [9-11]. Based on different chemical compositions, phase change materials can be classified as organic PCMs, inorganic PCMs, and organic-inorganic mixture PCMs. According to previous studies, organic PCMs possess a number of advantages, such as favourable chemical stability, good thermal stability, low cost, inconspicuous supercooling, and no phase separation [12,13]. However organic PCMs have several deficiencies, such as low thermal conductivity and liquid leakage and erosion during melting, which hinder the application of PCMs in many fields [11,14].

To solve the above problems, matrixes, such as multi-walled nanotubes, expanded graphite, mesoporous silica, activated carbon, among others, were introduced as supports for organic PCMs to synthesize shape stabilized PCMs. Liu et al. [15] prepared a novel form-stable phase change material containing meso-porous carbon and n-octadecane, which had excellent phase change behaviour and a fast thermal-response rate. Li et al. [16] synthesized organic montmorillonite (OMMT)/paraffin/grafted multi-walled nanotube (MWNT) composite phase change material, and the thermal conductivity of OMMT/paraffin increased $34 \%$ by adding grafted MWNTs. Ramakrishnan et al. [17] reported a novel composite phase change material (paraffin/EPO) synthesized by a vacuum impregnation method, which included paraffin and hydrophobic expanded perlite (EPO), and the paraffin/EPO exhibited good chemical compatibility and thermal stability. Zhang et al. [18] investigated composite PCMs which utilized silica matrices as the support for paraffin for thermal energy storage, and the results showed that the scaffold of silica matrices with large specific surface areas could improve the phase change properties of the paraffin, and this approach was cost-effective and had great practical application potentials.

Inspired by the strong adhesion of proteins secreted by mussels, Messersmith's [19] group reported a biomimetic method for surface modification using dopamine (DA). Dopamine can be oxidized and self-polymerized in a weak alkaline aqueous solution, forming a polydopamine (PDA) coating with strong adhesion to the surfaces of a wide variety of materials [20]. These properties endow it with a wide range of applications, such as drug delivery, biosensors, adsorption, etc. [21-24]. Moreover, dopamine can be oxidized and self-polymerized to form polydopamine microspheres (PDAMs) using a biomimetic synthesis method, and PDAMs can be used as excellent adsorbents to remove pollutants in wastewater. For instance, Zhang et al. [20] used polydopamine microspheres as efficient adsorbents for the removal of $\mathrm{Cr}(\mathrm{VI})$ in industrial effluent. Khalil and Neda [25] utilized polydopamine microspheres as novel nanobiopolymers for the biosorption of L-cysteine from aqueous solutions. Inspired by the strong adsorption capacity of polydopamine microspheres toward various organic materials, in this study, PDAMs were synthesized and used as carriers of organic phase change material. Moreover, the preparation of PDAMs is relatively easy, has mild conditions, low energy consumption, and is non-toxic [26,27]. Additionally, to the best of our knowledge, there are no studies on form-stable phase change materials using PDAMs as a support thus far.

Polyethylene glycol (PEG) is a widely used organic phase change material, which has the advantages of a non-toxic nature, high thermal stability, and large latent heat storage [28,29], and therefore, in this work, PDAMs were first synthesized using a biomimetic method, and then they were used to form a matrix of PEG in order to develop a novel and efficient form-stable phase change material (PEG/PDAM) using a simple method of vacuum impregnation. A schematic representation of the preparation process of PEG/PDAMs is shown in Figure 1. The interaction mechanism between PEG and PDAMs was studied, and the properties of PEG/PDAMs, such as phase change behaviour, surface morphology, thermal stability, and reliability were investigated. The results demonstrated that PEG/PDAMs can be used as an efficient energy storage material due to the fact of its high latent heat storage capacity and excellent thermal stability and reliability. 


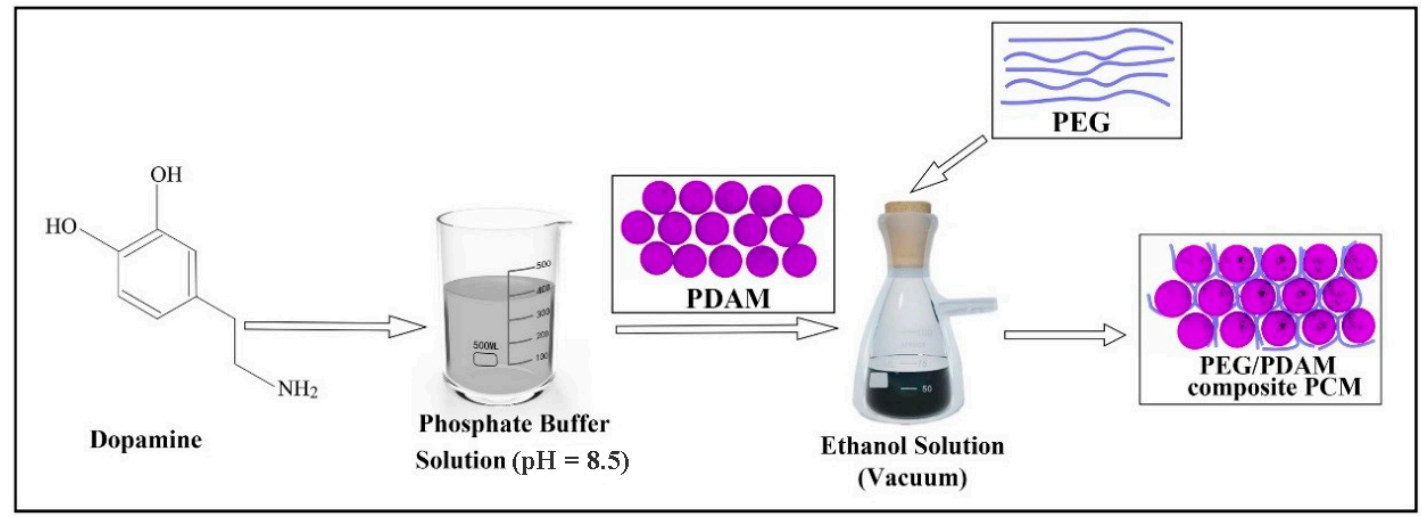

Figure 1. Schematic representation of the preparation process of polyethylene glycol (PEG)/polydopamine microspheres (PDAMs).

\section{Experimental Section}

\subsection{Materials}

Dopamine hydrochloride was purchased from Sigma-Aldrich (St. Louis, MI, USA). Sodium phosphate dibasic anhydrous and sodium phosphate monobasic anhydrous were purchased from Sinopharm Chemical Reagent Co. LTD (Shanghai, China). Polyethylene glycol was purchased from Aladdin Industrial Corporation (Shanghai, China).

\subsection{Preparation of PDAMs}

The PDAMs were prepared by oxidative polymerization. Phosphate buffer solution with a $\mathrm{pH}$ of 8.5 was prepared using hydrogen disodium phosphate and sodium dihydrogen phosphate. Specifically, the phosphate buffer solution $(50 \mathrm{~mL})$ and dopamine hydrochloride $(0.25 \mathrm{~g})$ were mixed in the beaker $(500 \mathrm{~mL})$ to form a homogeneous solution by magnetic stirring (500 rpm) at $25^{\circ} \mathrm{C}$ for $24 \mathrm{~h}$. The homogeneous solution was filtered, and then dried for $12 \mathrm{~h}$ in an oven at $45^{\circ} \mathrm{C}$ to obtain PDAM.

\subsection{Preparation of PEG/PDAM Composite Materials}

Both PEG-4000 and PDAM were used to prepare PEG/PDAM composite materials. Firstly, different concentrations of PEG-4000 solutions were prepared by adding certain amounts of PEG-4000 ( $0.061 \mathrm{~g}$, $0.093 \mathrm{~g}, 0.15 \mathrm{~g}$, and $0.20 \mathrm{~g}$ ) to $10 \mathrm{~mL}$ anhydrous ethanol, respectively. Then, a certain quantity of PDAMs $(0.05 \mathrm{~g}, 0.05 \mathrm{~g}, 0.05 \mathrm{~g}$, and $0.05 \mathrm{~g})$ were blended into the above dissolved solutions, respectively. The mixed solutions were stirred in a vacuum impregnation for $1 \mathrm{~h}$. After that, those mixtures were put in a thermostatic water bath at $45^{\circ} \mathrm{C}$ for $4 \mathrm{~h}$. Finally, the mixed solutions were dried at $45^{\circ} \mathrm{C}$ for $12 \mathrm{~h}$, and the PEG/PDAM composite materials were acquired, which were then labelled PEG/PDAM-1, PEG/PDAM-2, PEG/PDAM-3, and PEG/PDAM-4, respectively.

\subsection{Characterization}

The size and morphology of the PDAMs and PEG/PDAMs were examined at $10.0 \mathrm{kV}$ by scanning electron microscopy (SEM) with a FEG-250, FEI instrument (Waltham, MA, USA), and the microstructure of the PDAMs was determined by transmission electron microscopy (TEM) with a JEM-2100F, JEOL instrument (Tokyo, Japan). The characteristic functional groups of the PDAMs, PEG/PDAMs, and PEG were ascertained by Fourier transform infrared spectroscopy (FTIR) with a Bruker VECTOR22 system (Karlsruhe, Germany), and the infrared spectra wavenumber range from 500 to $4000 \mathrm{~cm}^{-1}$. The crystallization behaviour of the PDAMs, PEG/PDAMs, and PEG were investigated by X-ray diffraction (XRD) with a DX-2700, SHL-2 system from Thermo Scientific (Waltham, MA, USA), which was carried out at $40 \mathrm{kV}$ and $40 \mathrm{~mA}$ with a diffraction angle ranging from $10^{\circ}$ to $60^{\circ}$. The phase change properties of PEG/PDAMs and PEG were analysed using a differential scanning calorimeter (DSC) 
with a DSC Q200 system, NETZSCH (Munich, Germany), which aimed to determine the melting and crystallization behaviours of the PEG/PDAMs, and the experiments were carried out from $0^{\circ} \mathrm{C}$ to $100^{\circ} \mathrm{C}$ with a heating and cooling rate of $10^{\circ} \mathrm{C} / \mathrm{min}$ under a high purity nitrogen atmosphere. The specific surface areas and pore volumes of the PDAMs were obtained using the Brunauer-Emmett-Teller (BET) method with a Nova 2000 e, Quanta (Waltham, MA, USA) which were carried out at $77.3 \mathrm{~K}$ with nitrogen as the analysis gas. The surface chemical compositions of the PDAMs and PEG/PDAMs were measured by X-ray photoelectron spectroscopy (XPS) with an 250Xi K-Alpha system from Thermo Fisher (Waltham, MA, USA). The thermal stability of the PDAMs and PEG/PDAMs were investigated by thermogravimetric analysis (TGA) with a NETZSCH, 209F3 (Selb, Bavaria, Germany), which were conducted from $50^{\circ} \mathrm{C}$ to $550{ }^{\circ} \mathrm{C}$ with a heating rate of $10^{\circ} \mathrm{C} / \mathrm{min}$ under a high purity nitrogen atmosphere. For leakage tests, the pure PEG and the composite form-stable PCMs were pressed into small wafers, and these small wafers were placed in an oven at $70{ }^{\circ} \mathrm{C}$ for $10 \mathrm{~min}$. If leakage occurred for the PEG/PDAM composites, stains of PEG were left on the filter papers.

\section{Results and Discussion}

\subsection{Characterization of PDAMs and PEG/PDAMs}

Figure 2 shows the TEM images of the PDAMs and SEM images of the PDAM and PEG/PDAM composites. The TEM images of the PDAMs are shown in Figure 2a,b, which indicated that the PDAMs were a solid structure. Figure 2c shows the SEM image of the PDAMs, and it is clear that the PDAMs had irregular shapes on their outer surface. As is shown in Figure $2 \mathrm{~d}-\mathrm{f}$, the SEM images of PEG/PDAM-1, PEG/PDAM-2, and PEG/PDAM-3 revealed that the PEG distributed on the surface of all the PEG/PDAM composites, and compared with the images of PEG/PDAM-1 and PEG/PDAM-2, nearly all surfaces of PEG/PDAM-3 were enwrapped with PEG, which might be due to the hydrogen bonds interaction between the PEG molecules and PDAM.
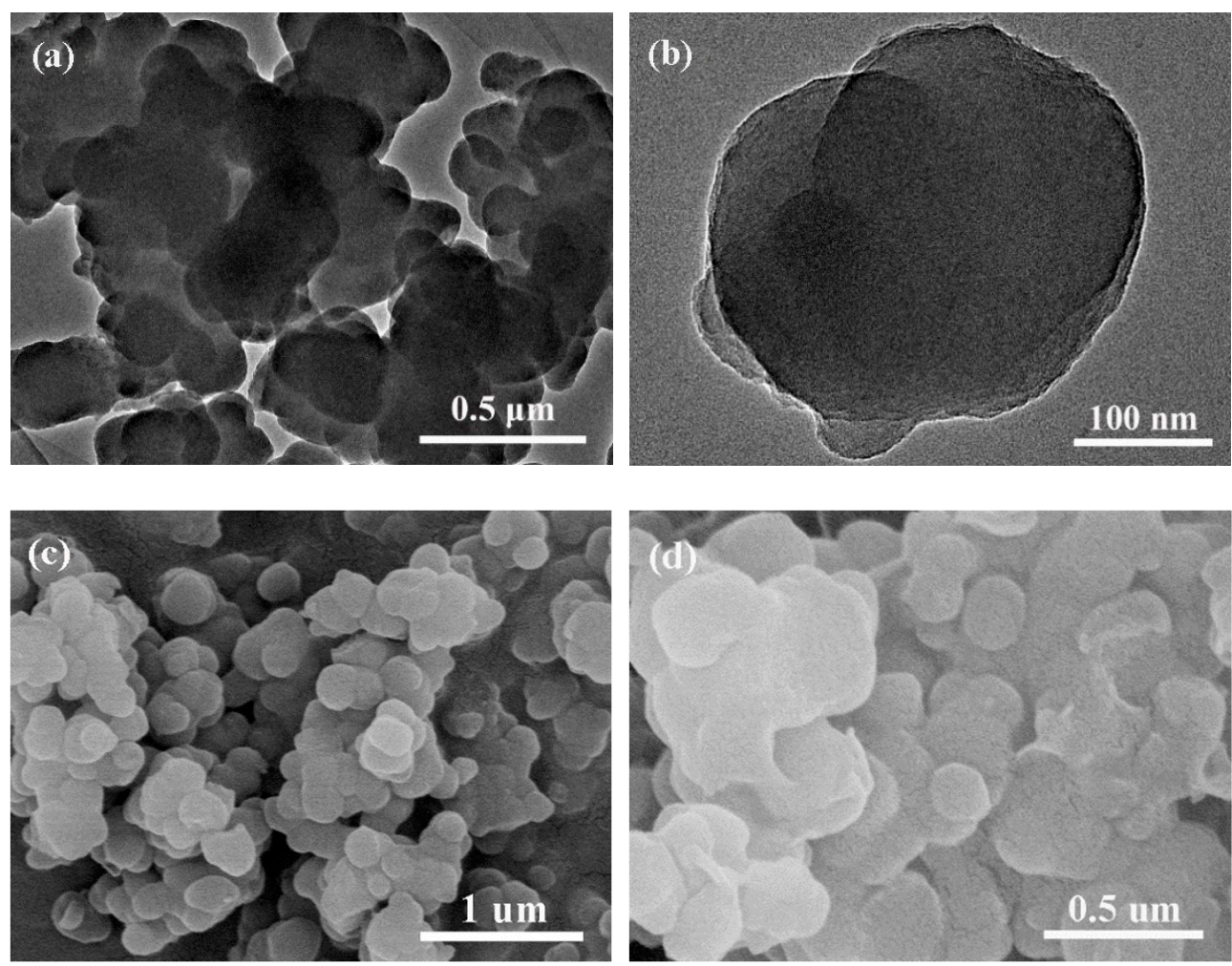

Figure 2. Cont. 

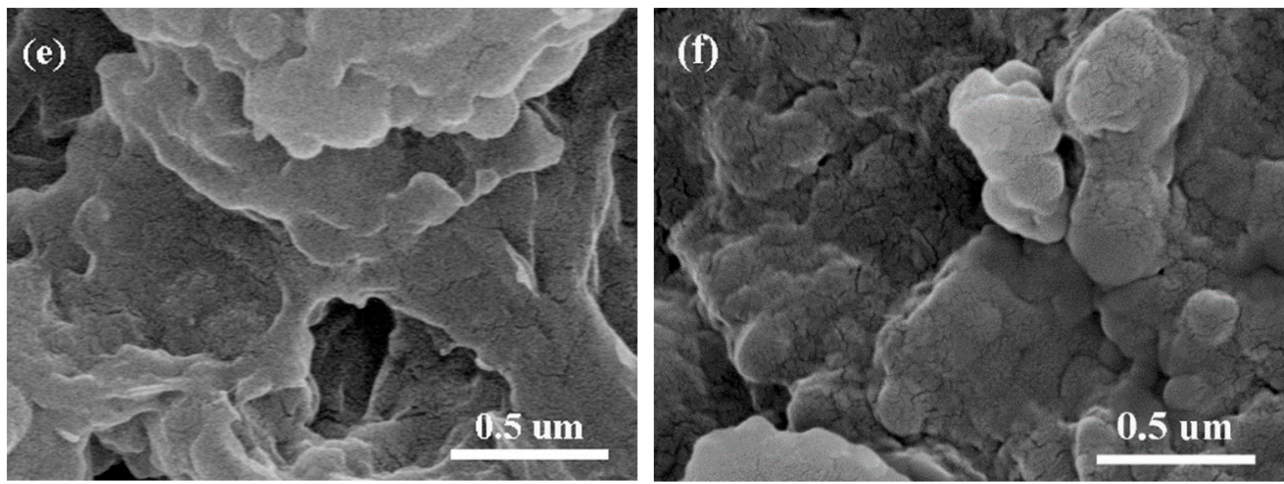

Figure 2. TEM images of PDAMs (a,b), SEM image of PDAMs (c), PEG/PDAM-1 (d), PEG/PDAM-2 (e), and PEG/PDAM-3 (f).

\subsection{The Nitrogen Adsorption-Desorption Isotherm of the PDAMs}

Figure 3 shows the nitrogen adsorption-desorption isotherms of the PDAMs obtained at $77.3 \mathrm{~K}$. The surface area of the PDAM nanoparticles was $11.21 \pm 0.72 \mathrm{~m}^{2} / \mathrm{g}$, which was calculated by the BET method. The average pore volume and pore diameter size were calculated to be $0.014 \pm 0.0015 \mathrm{~cm}^{3} / \mathrm{g}$ and $3.20 \pm 0.18 \mathrm{~nm}$, respectively. Because the PDAMs were a solid structure, the pores originated from the gaps among the polydopamine particles, and the nitrogen adsorption-desorption isotherms of the PDAMs was a type IV isotherm, which indicated that the gaps between the polydopamine particles were mesoporous intervals [30]. More importantly, the large pore diameter of the PDAMs was beneficial for the entrance and accommodation of PEG.

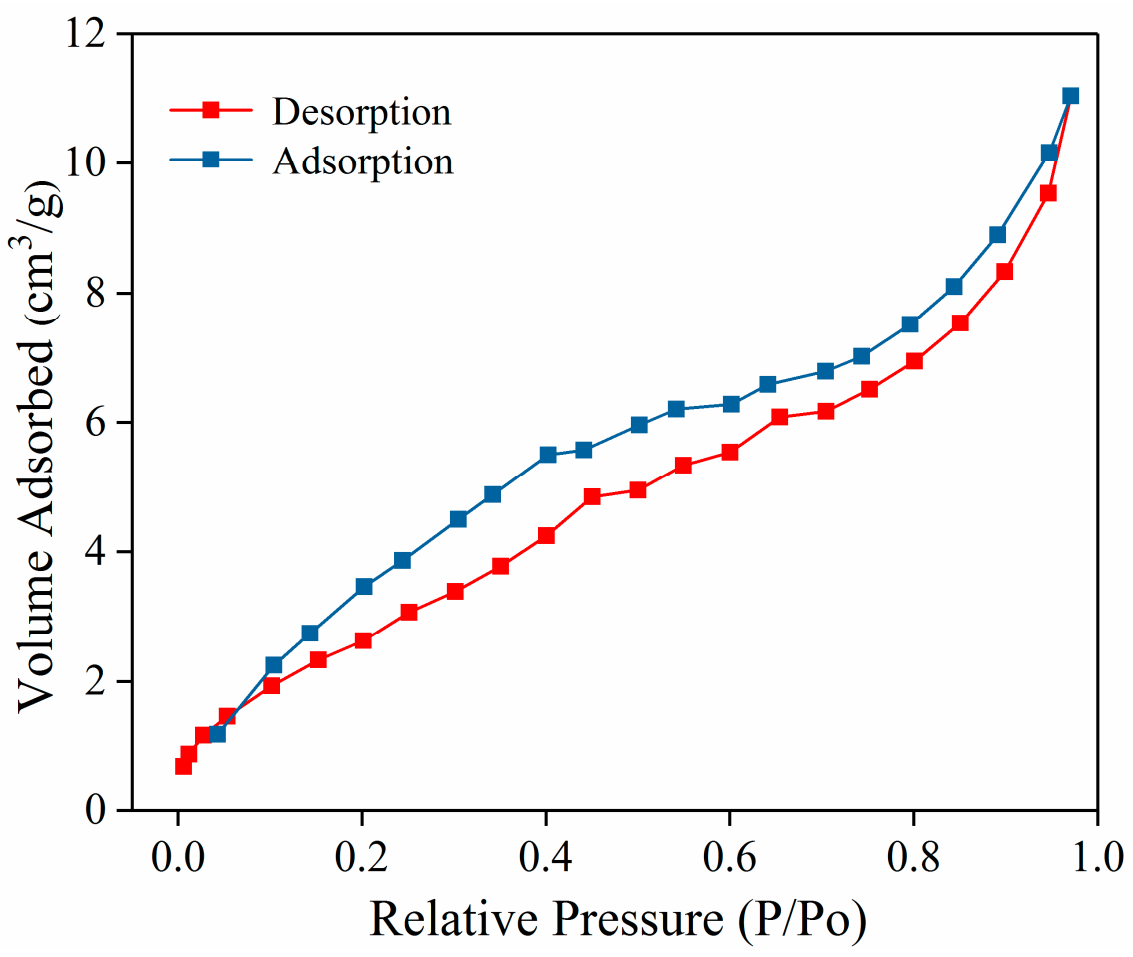

Figure 3. $\mathrm{N}_{2}$ adsorption/desorption isotherms of the PDAMs.

\subsection{Leakage Tests of PEG and PEG/PDAM Composites}

Figure 4 shows the leakage test results of pure PEG and PEG/PDAM composites. In the leakage test experiments, if leakage occurred for the PEG/PDAM composites, it left stains of PEG on the filter papers. As shown in Figure 4c, the small wafer of PEG quickly melted into liquid at $70{ }^{\circ} \mathrm{C}$. Meanwhile, 
the PEG/PDAM-1, PEG/PDAM-2, and PEG/PDAM-3 remained intact and did not show any leakage on the filter paper, which could be attributed to the large adsorption capacity of the PDAMs for the PEG endowing the PEG/PDAM-1, PEG/PDAM-2, and PEG/PDAM-3 with the favourable ability to prevent leakage. However, PEG/PDAM-4 in Figure 4c showed traces of melted PEG, which indicated that liquid leakage occurred for PEG/PDAM-4, and the content of PEG in PEG/PDAM-4 exceeded the load capacity of PDAM. Therefore, on the premise of no leakage appearance, PEG/PDAM-3 could immobilize the largest amount of PEG in this study and, hence, PEG/PDAM-3 served as the main object for researching the thermal properties of the form-stable PCMs.

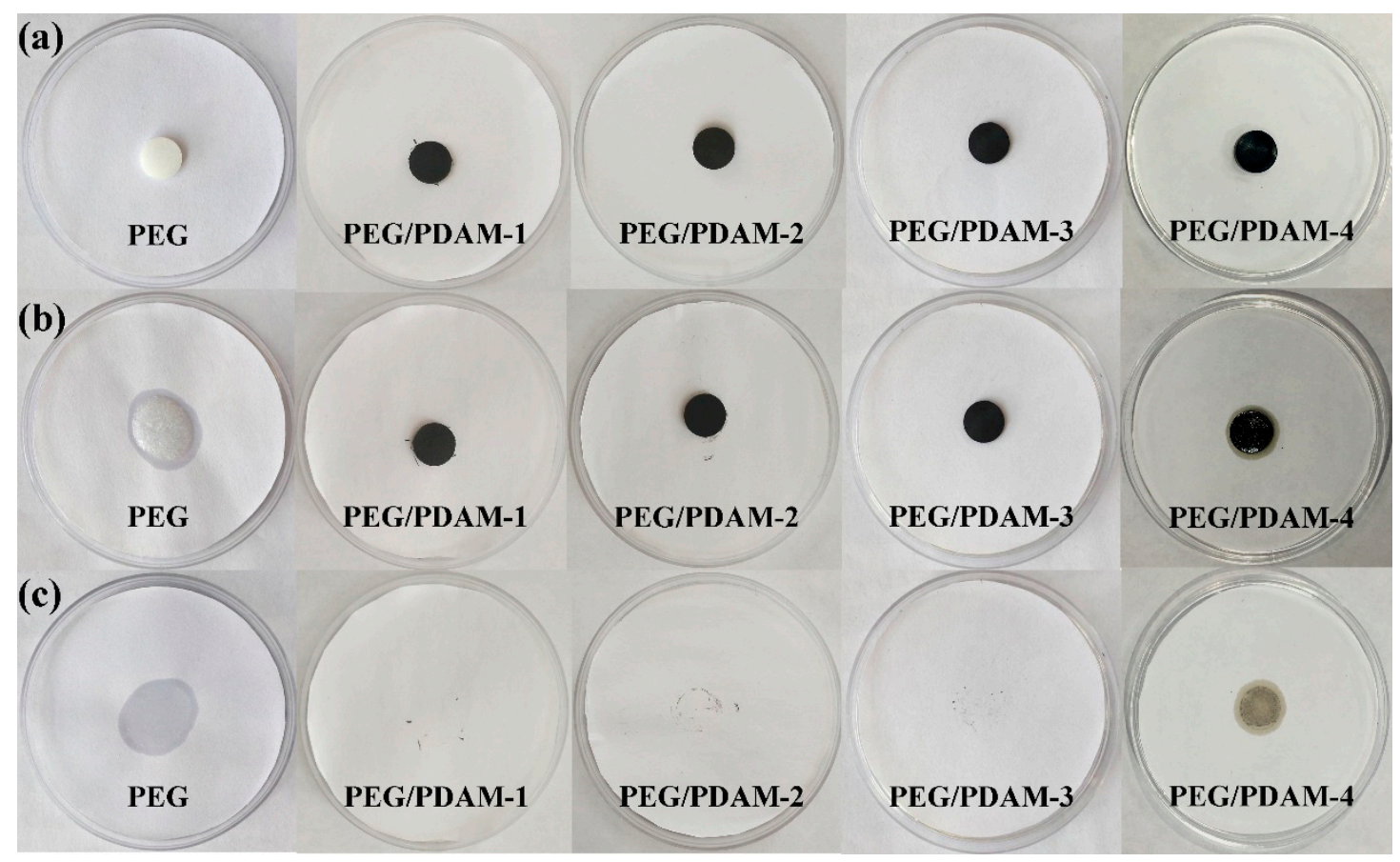

Figure 4. Leakage test photographs of PEG, PEG/PDAM-1, PEG/PDAM-2, PEG/PDAM-3, and PEG/PDAM-4.: (a) pictures of samples before the thermal stability test; (b) pictures of samples after the thermal stability test; (c) pictures of leakage trace after the removal of samples.

\subsection{XRD Patterns of PEG, PDAM, and PEG/PDAM Composites}

The XRD patterns of PEG, PDAM, PEG/PDAM-1, PEG/PDAM-2, and PEG/PDAM-3 are shown in Figure 5, where the ordinate values represent the $X$-ray diffraction intensity and the abscissa values represent the X-ray diffraction angle. The XRD curve of the PDAMs was a flatter curve, and there was no distinct diffraction peak, which indicated that the PDAMs were amorphous [22]. In the XRD curve of pure PEG, there were two sharp and acute diffraction peaks at $19.18^{\circ}$ and $23.29^{\circ}$, respectively. The diffraction peak at $19.18^{\circ}$ belonged to the $\{120\}$ plane, and the diffraction peak at $23.29^{\circ}$ represents \{032\} Miller planes of the monoclinic unit cell [31]. The XRD curve of PEG/PDAM-1 appeared at two diffraction peaks at $19.08^{\circ}$ and $23.20^{\circ}$, and for the curve of PEG/PDAM-2, there were also two diffraction peaks at $19.20^{\circ}$ and $23.40^{\circ}$. Similarly, two typical diffractions peaks at $18.98^{\circ}$ and $23.16^{\circ}$ could also be observed in the curves of PEG/PDAM-3. It was clear that no new diffraction peak appeared in the XRD curve of the PEG/PDAM composites, and the crystal structure of PEG was almost unchanged in the composite materials of PEG/PDAM-1, PEG/PDAM-2, and PEG/PDAM-3. The latent heat absorption and release of the composites PEG/PDAM was due to the crystallization behaviour of PEG molecules [32], and the crystallization process of PEG included two parts, nucleation of the crystal and growth. In the early period of PEG molecule crystallization, the thermal fluctuations of the polymer chains induced the primary nucleation of the crystal and, subsequently, the stable crystalline phase grew continuously [12]. The diffractions peaks of the XRD curve of the PEG/PDAM composites were 
significantly lower than that of the pure PEG, which indicated that the interaction between PEG and the PDAMs prevented the crystallization behaviour of PEG molecules [6]. However, it was found that the diffraction peaks of PEG/PDAM-3 was higher than that of PEG/PDAM-1 and PEG/PDAM-2, which demonstrated that with the increase of PEG content in the PEG/PDAM composites, the crystallinity of the composite shape-stabilized phase change materials increased. Furthermore, the results also revealed that the synthesis process of the PEG/PDAM composites was only a physical interaction without any chemical interaction between the PEG molecules and the PDAMs, as there was no change in the crystalline structure of the PEG in the composite phase change materials.

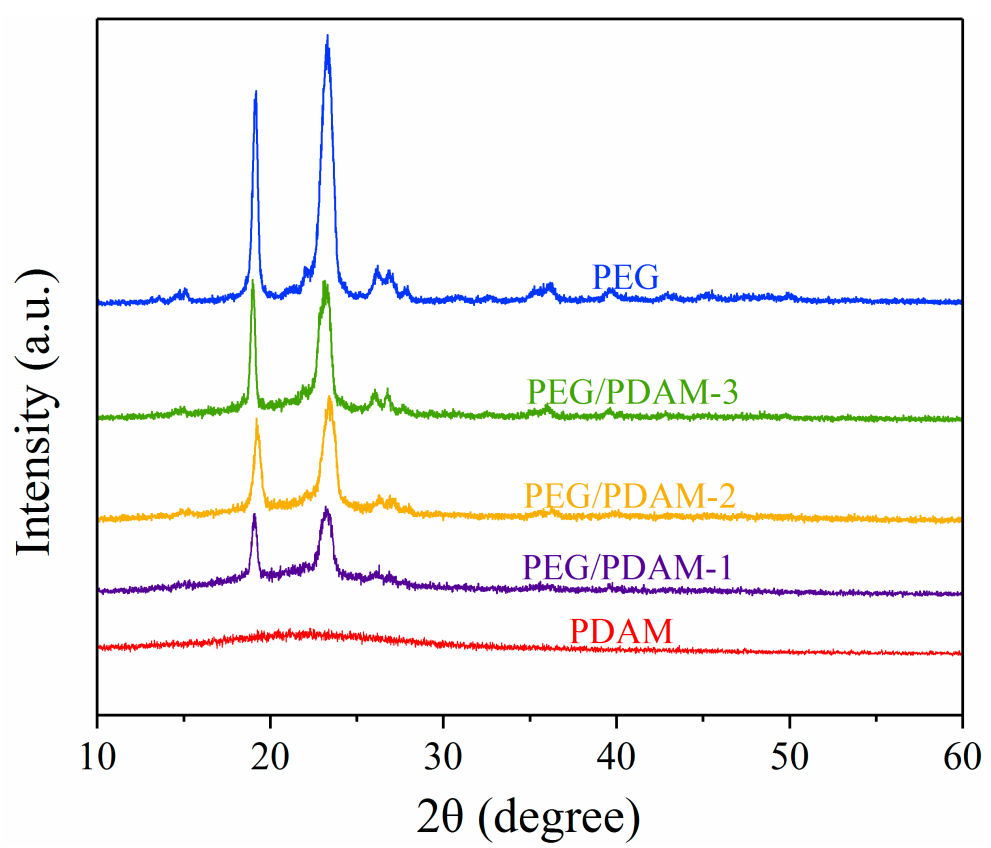

Figure 5. XRD patterns of PEG, PEG/PDAM-1, PEG/PDAM-2, PEG/PDAM-3, and PDAMs.

\subsection{Chemical Properties}

The FTIR spectra of PEG, PDAMs, PEG/PDAM-1, PEG/PDAM-2, and PEG/PDAM-3 are shown in Figure 6, and in the figure, the ordinate values represent the infrared ray transmittance and the abscissa values represent the infrared ray wavenumber. For the FTIR spectrum of PEG, many narrow peaks were found at $842,963,1060,1113,1149,1343,1467,1622,2888$, and $3420 \mathrm{~cm}^{-1}$, and the peak at $3420 \mathrm{~cm}^{-1}$ was attributed to the stretching vibration of the $\mathrm{O}-\mathrm{H}$ functional group [33]. The peaks at 842,963 , and $2888 \mathrm{~cm}^{-1}$ were ascribed to the stretching vibration of $-\mathrm{CH} 2$ groups [34], and the peak at $1113 \mathrm{~cm}^{-1}$ was attributed to the stretching vibration of the $\mathrm{C}-\mathrm{O}$ groups [35]. The peak at $1622 \mathrm{~cm}^{-1}$ was ascribed to the stretching of water molecules, and the absorption peaks at $1343 \mathrm{~cm}^{-1}$ and $1467 \mathrm{~cm}^{-1}$ represented the stretching vibration of $\mathrm{C}-\mathrm{H}$ groups [36]. For the FTIR spectrum of the PDAMs, the adsorption band at $3420 \mathrm{~cm}^{-1}$ was considered the stretching vibration of phenolic $\mathrm{O}-\mathrm{H}$ groups and $\mathrm{N}-\mathrm{H}$ groups [37]. The peak at $1622 \mathrm{~cm}^{-1}$ was considered the stretching vibration of aromatic rings and bending vibration of $\mathrm{N}-\mathrm{H}$ groups [38,39]. The peaks at 1506 and $1113 \mathrm{~cm}^{-1}$ were associated with the $\mathrm{N}-\mathrm{H}$ shearing vibration of the amide group and the vibration of $\mathrm{C}-\mathrm{O}$ groups, respectively. The peaks at 1343 and $1288 \mathrm{~cm}^{-1}$ could be attributed to the phenolic $\mathrm{C}-\mathrm{O}-\mathrm{H}$ bending and stretching vibration, respectively [6]. The FTIR spectra of PEG/PDAM-1, PEG/PDAM-2, and PEG/PDAM-3 were quite similar to those of PEG and PDAMs, except for some slight variation, which indicated that there was only physical interaction in the synthetic process rather than a chemical reaction. 


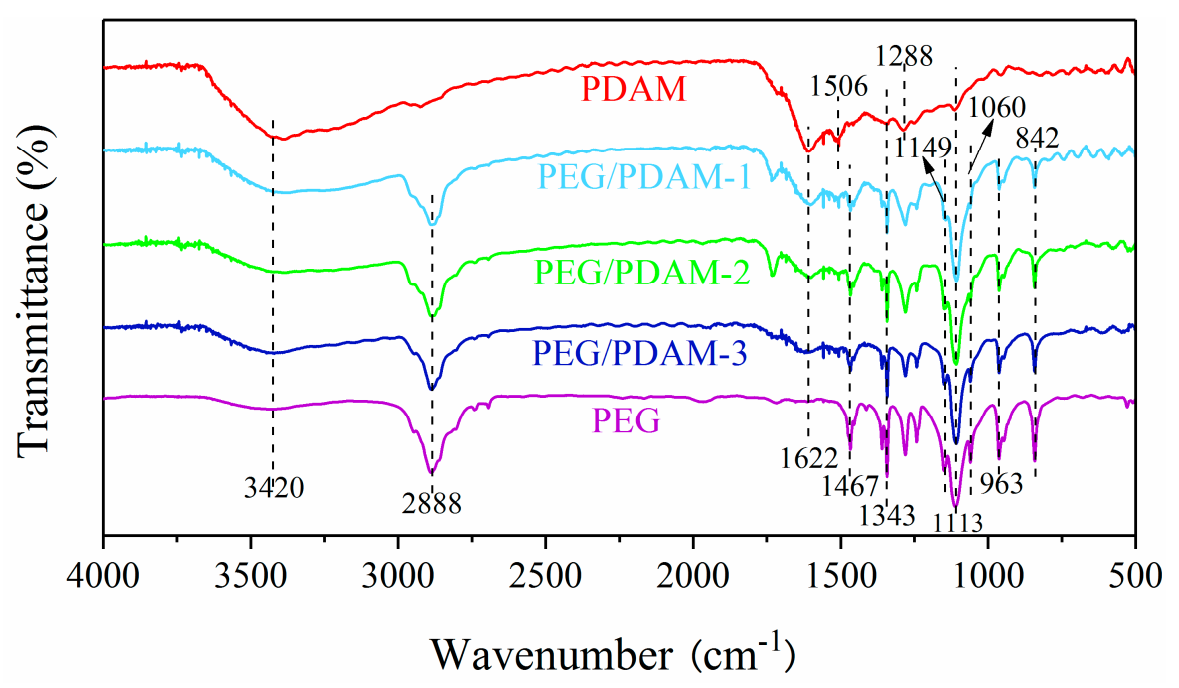

Figure 6. FTIR spectra of PEG, PEG/PDAM-1, PEG/PDAM-2, PEG/PDAM-3, and PDAM.

\subsection{Latent Heat Storage Analysis}

The DSC was used to investigate the melting and crystallizing behaviours of phase change materials. According to the DSC test results, the melting and crystallizing enthalpies of the pure PEG and PEG/PDAM composites are summarized in Table 1. As shown in Figure 7, the DSC curves of the PEG/PDAM composites exhibited a similar shape with that of PEG, meaning that the PEG mainly acted as latent thermal energy storage material during the phase change process. In Table 1 , the melting peak temperatures and freezing peak points of the pure PEG were measured as $63.30 \pm 0.60{ }^{\circ} \mathrm{C}$ and $35.95 \pm$ $0.35^{\circ} \mathrm{C}$, respectively, and the melting and freezing latent heats of PEG reached to $227.40 \pm 2.00 \mathrm{~J} / \mathrm{g}$ and $207.10 \pm 0.00 \mathrm{~J} / \mathrm{g}$, respectively. Meanwhile, the PEG/PDAM-1 had fusion and solidification enthalpies of $82.57 \pm 4.27 \mathrm{~J} / \mathrm{g}$ and $66.10 \pm 4.16 \mathrm{~J} / \mathrm{g}$, respectively, and its melting and freezing peak points were 60.95 $\pm 0.15{ }^{\circ} \mathrm{C}$ and $28.05 \pm 1.05{ }^{\circ} \mathrm{C}$, respectively. The fusion and solidification enthalpies of PEG/PDAM-2 reached $108.65 \pm 1.85 \mathrm{~J} / \mathrm{g}$ and $91.17 \pm 2.44 \mathrm{~J} / \mathrm{g}$, respectively, and the melting peak point of PEG/PDAM-2 was $62.00 \pm 0.00{ }^{\circ} \mathrm{C}$ and its freezing peak point was $29.80 \pm 0.80{ }^{\circ} \mathrm{C}$. The fusion and solidification enthalpies of PEG/PDAM-3 reached $133.20 \pm 2.50 \mathrm{~J} / \mathrm{g}$ and $107.55 \pm 4.45 \mathrm{~J} / \mathrm{g}$, respectively, and its melting and freezing peak points were at $62.20 \pm 0.00{ }^{\circ} \mathrm{C}$ and $31.10 \pm 0.60{ }^{\circ} \mathrm{C}$, respectively. The latent heat value of PEG/PDAM composites with different PEG contents was lower than that of pure PEG, and with increasing PEG contents, the latent heat value of the PEG/PDAM composites were increased. 
Table 1. Phase change temperatures and latent heat values of the PEG and PEG/PDAM composites ${ }^{\text {a }}$.

\begin{tabular}{|c|c|c|c|c|c|c|c|c|}
\hline Samples & $T_{\text {mo }}\left({ }^{\circ} \mathrm{C}\right)$ & $T_{\mathrm{mp}}\left({ }^{\circ} \mathrm{C}\right)$ & $T_{\text {me }}\left({ }^{\circ} \mathrm{C}\right)$ & $\Delta H_{\mathrm{m}}(\mathrm{J} / \mathrm{g})$ & $T_{\text {co }}\left({ }^{\circ} \mathrm{C}\right)$ & $T_{\mathrm{cp}}\left({ }^{\circ} \mathrm{C}\right)$ & $T_{\text {ce }}\left({ }^{\circ} \mathrm{C}\right)$ & $\Delta H_{\mathrm{c}}(\mathrm{J} / \mathrm{g})$ \\
\hline PEG/PDAM-1 & $56.00 \pm 0.00$ & $60.9 \pm 0.15$ & $65.45 \pm 1.05$ & $82.57 \pm 4.27$ & $23.70 \pm 1.40$ & $28.05 \pm 1.05$ & $34.75 \pm 0.05$ & $66.10 \pm 4.16$ \\
\hline PEG/PDAM-2 & $54.55 \pm 0.95$ & $62.00 \pm 0.00$ & $66.10 \pm 0.70$ & $108.65 \pm 1.85$ & $25.10 \pm 1.10$ & $29.80 \pm 0.80$ & $34.50 \pm 2.00$ & $91.17 \pm 2.44$ \\
\hline PEG/PDAM-3 & $57.35 \pm 0.05$ & $62.20 \pm 0.00$ & $68.00 \pm 0.50$ & $133.20 \pm 2.50$ & $26.80 \pm 0.80$ & $31.10 \pm 0.60$ & $35.90 \pm 0.80$ & $107.55 \pm 4.45$ \\
\hline PEG & $59.05 \pm 0.15$ & $63.30 \pm 0.60$ & $66.05 \pm 0.85$ & $227.40 \pm 2.00$ & $32.30 \pm 0.10$ & $35.95 \pm 0.35$ & $40.25 \pm 0.65$ & $207.10 \pm 0.00$ \\
\hline
\end{tabular}

a $T_{\mathrm{mo}} T_{\mathrm{mp}}$ and $T_{\mathrm{me}}$ are the onset, the peak and the end of the melting phase change temperature respectively. $T_{\mathrm{co}} T_{\mathrm{cp}}$, and $T_{\mathrm{ce}}$ are the onset the peak, and the end of the freezing phase change temperature, respectively. $\Delta H_{\mathrm{m}}$ and $\Delta H_{\mathrm{c}}$ are the latent heat values in the melting process and in the freezing process, respectively. 


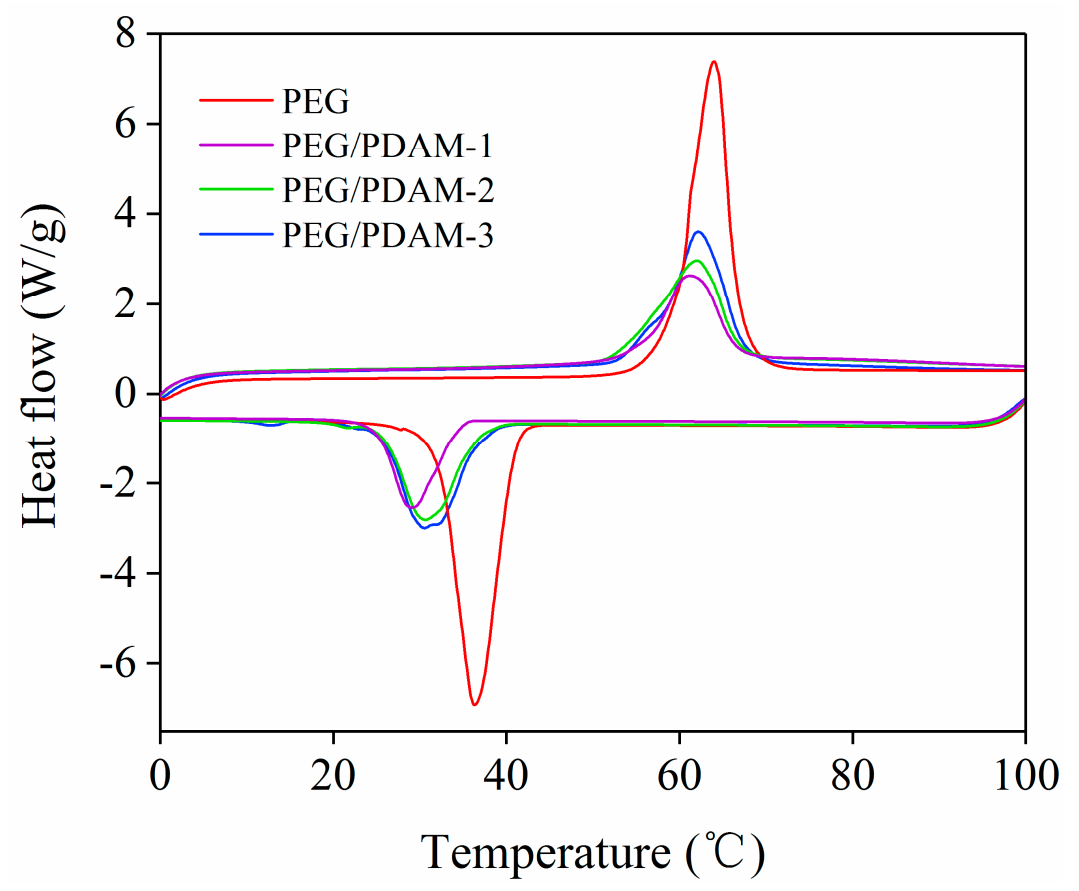

Figure 7. DSC curves of PEG and the samples.

The formation mechanism of polydopamine included four steps, which are shown in Figure 8. Firstly, dopamine formed dopamine quinone easily by oxidation. Secondly, o-dopaminoquinone was formed after the interchange between two electrons and two protons in dopamine molecules in alkaline condition. Quinones were facilely bound with nucleophiles because they have considerably high reactivity, and both the electron-deficient ring and electron-donating amine group were included in the dopaminoquinine $[40,41]$. Amine groups of dopamine were unprotonated, and cyclization reactions occurring in the molecule were undertaken in 1,4 Michael addition. Then, o-dopaminoquinone generates intramolecular cyclization through 1,4 Michael additions to form leucodopaminochrome. Finally, the leucodopaminochrome was easily oxidized and rearranged, and polydopamine was obtained by reaction and combination between numerous catechols and O-quinone [42].

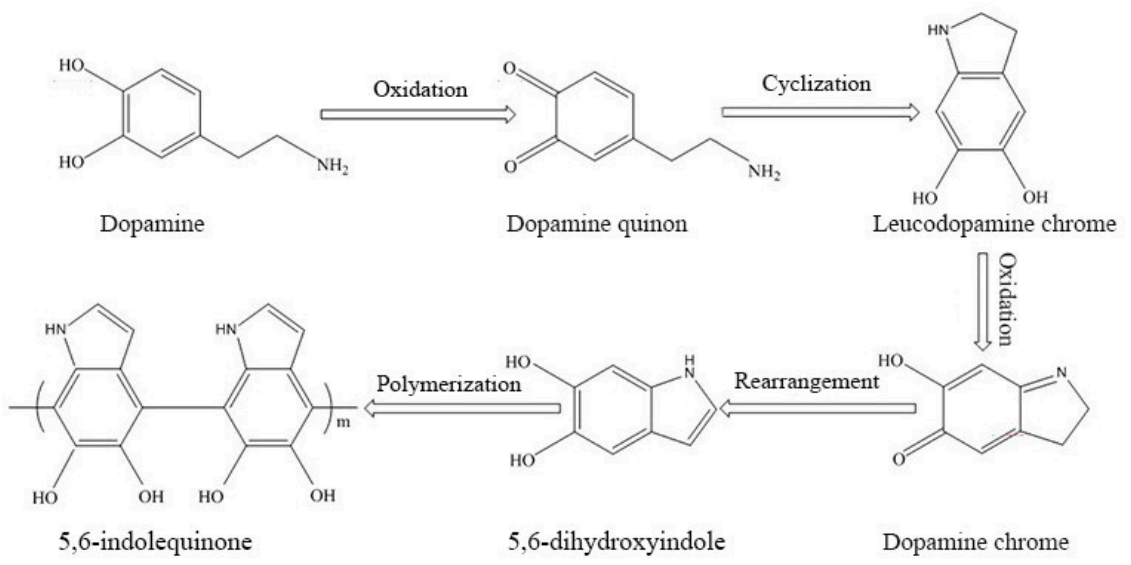

Figure 8. Formation mechanism of polydopamine.

According to the XRD test results, in the preparation process of PEG/PDAM, there was only physical interaction between the PEG molecules and PDAM and, therefore, PEG molecules were immobilized by PDAMs through the capillary force among the gaps of polydopamine microspheres. In addition, according to the FTIR test results, on the surface of PDAMs there were many amino and 
catechol groups, which can combine with PEG molecules to form hydrogen bonds [43]. The inferred interaction mechanism between PEG and the PDAMs is shown in Figure 9.

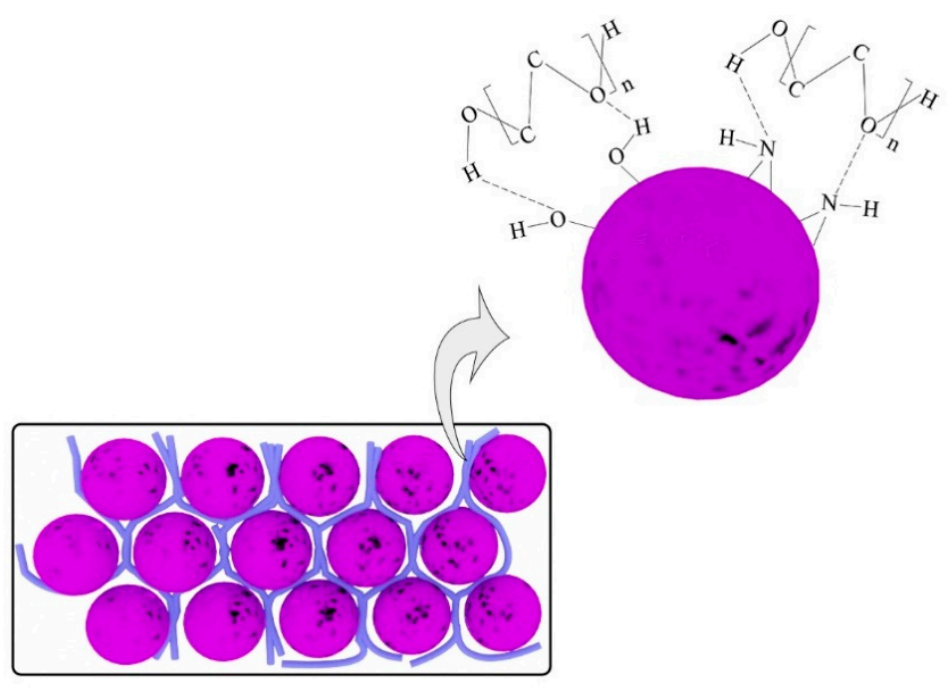

Figure 9. Inferred interaction mechanism between PEG and the PDAMs.

In addition to an excellent latent heat storage capacity of a form-stable PCM, it is also very important that form-stable PCMs have perfect thermal reliability. Therefore, thermal cycling tests were carried out to study the thermal reliability of PEG/PDAMs. As shown in Figure 10, the DSC curves of PFG/PDAM-3 before and after 50 thermal cycles changed at a negligible level, demonstrating that, according to the insignificant changes in temperatures and latent heats, PEG/PDAMs possessed excellent thermal reliability and could be repeatedly utilized in the field of thermal energy storage.

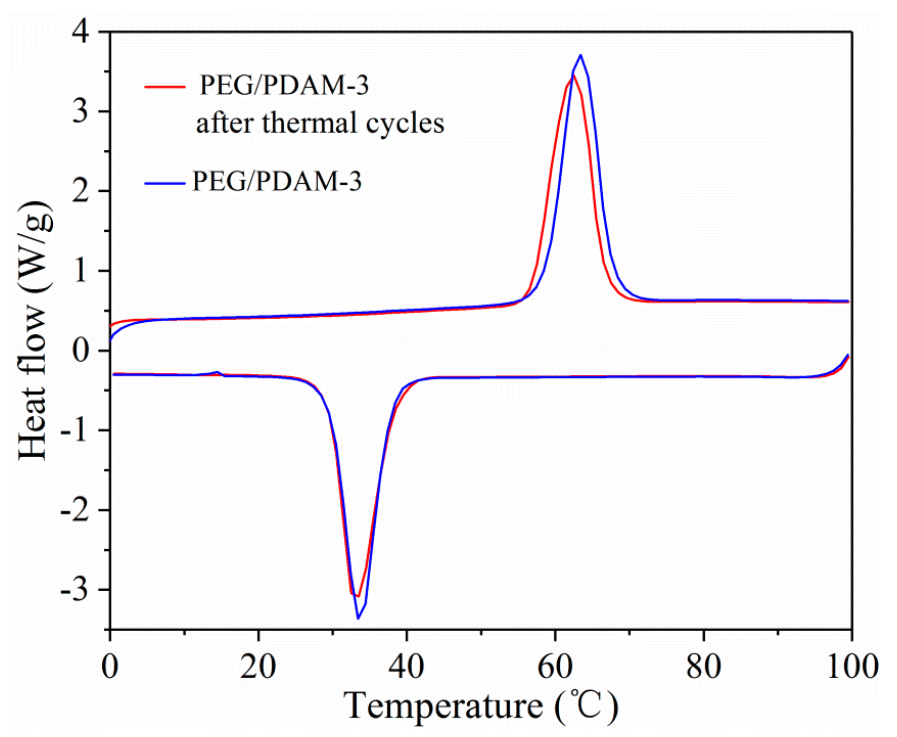

Figure 10. DSC curves of PEG/PDAM-3 before and after the thermal cycle.

\subsection{Thermal Stability of PEG/PDAM Composites}

Thermal stability is one of the most important parameters of phase change materials for thermal energy storage applications. Figure 11 shows the TGA curves of pure PEG, PDAM, and PEG/PDAM-3. For the sample of pure PEG, there was no distinct change before $310^{\circ} \mathrm{C}$. The TGA curve of pure PEG sharply dropped when the temperature increased from approximately $310^{\circ} \mathrm{C}$ to $410{ }^{\circ} \mathrm{C}$, and when the temperature was higher than $470^{\circ} \mathrm{C}$, there was little change, which demonstrated that pure PEG 
disintegrated completely, with a total weight loss of $98.28 \%$. The TGA curve of the PDAMs is shown in Figure 11, which was deemed to be the typical TGA curve of the PDAMs [32]. It quickly dropped in the temperature range of $50-550{ }^{\circ} \mathrm{C}$, and the total weight loss of the PDAMs was $37.40 \%$. For the sample of PEG/PDAM-3, the TGA curve showed no obvious change when the temperature was below $300{ }^{\circ} \mathrm{C}$. It was observed that the weight of PEG/PDAM-3 decreased rapidly in the temperature range of $300-410^{\circ} \mathrm{C}$. When the temperature was higher than $410^{\circ} \mathrm{C}$, there was a slow change in the weight loss curve of PEG/PDAM-3, and the total weight loss of PEG/PDAM-3 was $80.00 \%$.

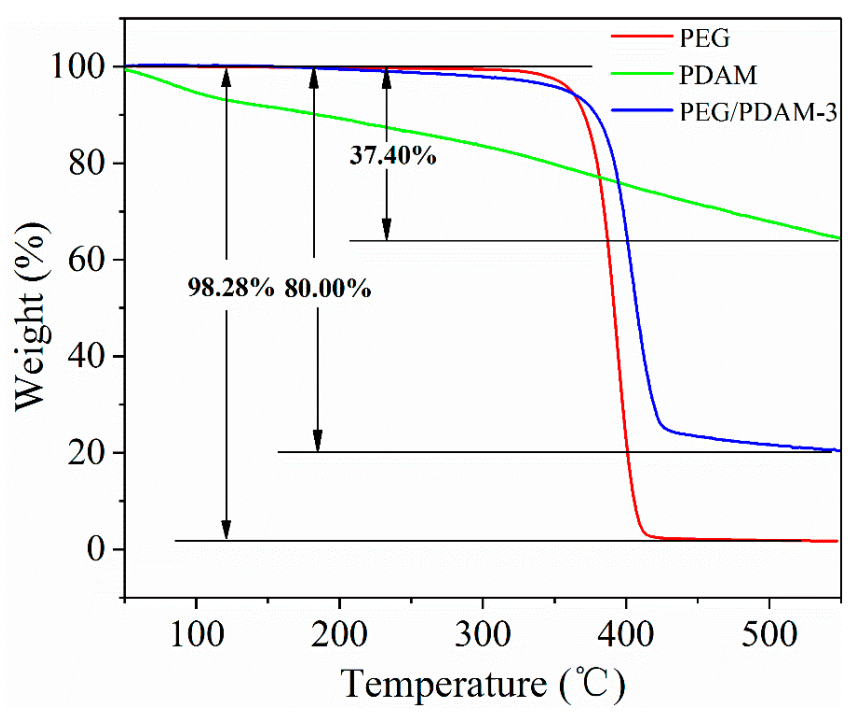

Figure 11. TGA curves of PEG, PDAMs, and PEG/PDAM-3.

According to the results of the TGA tests, the weight loss of pure PEG was $98.28 \%$, with $1.72 \%$ of PEG remaining undecomposed, which might be impurities or measurement errors in the tests. The PDAMs exhibited weight losses of $37.40 \%$, and the total weight loss of PEG/PDAM-3 was $80.00 \%$, which contained $10.00 \%$ decomposed PDAMs and $70.00 \%$ decomposed PEG. Therefore, the content of PEG in the composite of PEG/PDAM-3 was $70.00 \%$. Together with the DSC results of PEG/PDAM-3, the actual latent heat value of PEG/PDAM-3 decreased by $5.00 \%$ compared to the theoretical latent heat value of PEG/PDAM-3. This result might be ascribed to the capillary force and van der Waals force between the PDAMs and PEG molecules [43]. The TGA curve of the PDAMs quickly dropped before $200{ }^{\circ} \mathrm{C}$, but there was no obvious change for the TGA curve of PEG/PDAM-3 in the same process. This can be attributed to the content of the PDAMs in the PEG/PDAM-3 being relatively low and, therefore, the weight loss of the PDAMs had little influence on the change in the TGA curve of PEG/PDAM-3 before $200{ }^{\circ} \mathrm{C}$. When the temperature was higher than $410^{\circ} \mathrm{C}$, the curve of PEG/PDAM-3 dropped slowly because the PDAM was still decomposing. Moreover, for the composite of PEG/PDAM-3, the TGA curve did not significantly change before $300^{\circ} \mathrm{C}$, and hence, it is reasonable to believe that PEG/PDAM-3 exhibited favourable thermal stability.

\subsection{Structural Evolution of PDAMs and PEG/PDAM Composites}

To further investigate the surface chemical elemental compositions of the PDAMs and PEG/PDAM-3, XPS was carried out to analyse the main elements' interactions on the surface of the PDAMs and PEG/PDAM-3, and the results are shown in Figure 12, where the ordinate values represent the X-ray photoelectron intensity and the abscissa values represent the electron binding energy. For the XPS curves of the PDAMs, it was obvious that the C1s, N1s, and O1s were the main elements. The peaks of C1s, N1s, and O1s in the XPS curve of PEG/PDAM-3 were located at C-H $(284.9 \mathrm{eV}), \mathrm{C}-\mathrm{OH} / \mathrm{C}-\mathrm{N}$ $(286.1 \mathrm{eV}), \mathrm{C}=\mathrm{O}(287.4 \mathrm{eV}),-\mathrm{NH}(399.3 \mathrm{eV}),-\mathrm{NH} 2(400.1 \mathrm{eV}), \mathrm{C}=\mathrm{O}(532.1 \mathrm{eV})$, and $\mathrm{C}-\mathrm{OH}(532.7 \mathrm{eV})$, respectively. For the PDAMs, the $\mathrm{C} 1 \mathrm{~s}$ spectrum had four peak components with aromatic $\mathrm{C}-\mathrm{H}$ as the 
most distinct peak at $284.7 \mathrm{eV}$, and the $\mathrm{C}-\mathrm{OH} / \mathrm{C}-\mathrm{N}$ and $\mathrm{C}=\mathrm{O}$ peaks were located at the $286.0 \mathrm{eV}$ and $288.2 \mathrm{eV}$, respectively [44-46]. Furthermore, the $\pi-\pi$ bonding in the aromatic ring was a minor peak at $289.2 \mathrm{eV}$. Nevertheless, the intensity of $\pi-\pi$ bonding in the PEG/PDAM-3 spectrum was decreased, which implied the $\pi-\pi$ bonding mutual effect between the PDAM and PEG molecules [47]. Two obvious N1s peaks of PDAM were assigned to $-\mathrm{NH} 2(400.2 \mathrm{eV})$ and $-\mathrm{NH}(399.59 \mathrm{eV})$, respectively. For the N1s peaks of PEG/PDAM-3, the shifts of the two peaks of $-\mathrm{NH} 2(400.1 \mathrm{eV})$ and $-\mathrm{NH}(399.3 \mathrm{eV})$ were $0.1 \mathrm{eV}$ and $0.29 \mathrm{eV}$, respectively, and the $\mathrm{N}$ element mainly originated from the ammonium group of the PDAMs, which interacted with the $\mathrm{O}$ and $\mathrm{H}$ atoms in PEG molecules to form strong hydrogen bonds [48]. For the O1s peaks of the PDAMs, the peaks at $531.4 \mathrm{eV}$ and $533.0 \mathrm{eV}$ were assigned to the $\mathrm{C}=\mathrm{O}$ and $\mathrm{C}-\mathrm{OH}$, respectively. For the O1s peaks of the PEG/PDAM-3, the participation of PEG induced the shifts of two peaks of $\mathrm{C}=\mathrm{O}$ (532.1) and $\mathrm{C}-\mathrm{OH}$ (532.7) for $0.3 \mathrm{eV}$ and $0.7 \mathrm{eV}$, respectively, which implied that the catechol of the PDAM combined with the $\mathrm{O}$ and $\mathrm{H}$ atoms of PEG to form hydrogen bonds [43]. The XPS survey spectra curves of the PDAMs and PEG/PDAM-3 are shown in Figure 13. It was clear that three peaks could be found in the spectrum of the PDAM, and the spectrum of PEG/PDAM-3 had two high-intensity sharp peaks and one low-intensity peak, which belonged to $C, N$, and O. Furthermore, the N1s peak in the PEG/PDAM-3 spectrum was smaller compared with that in the spectrum of the PDAMs because the PEG did not contain $\mathrm{N}$ and, therefore, the content of $\mathrm{N}$ decreased in the composite of PEG/PDAM-3.
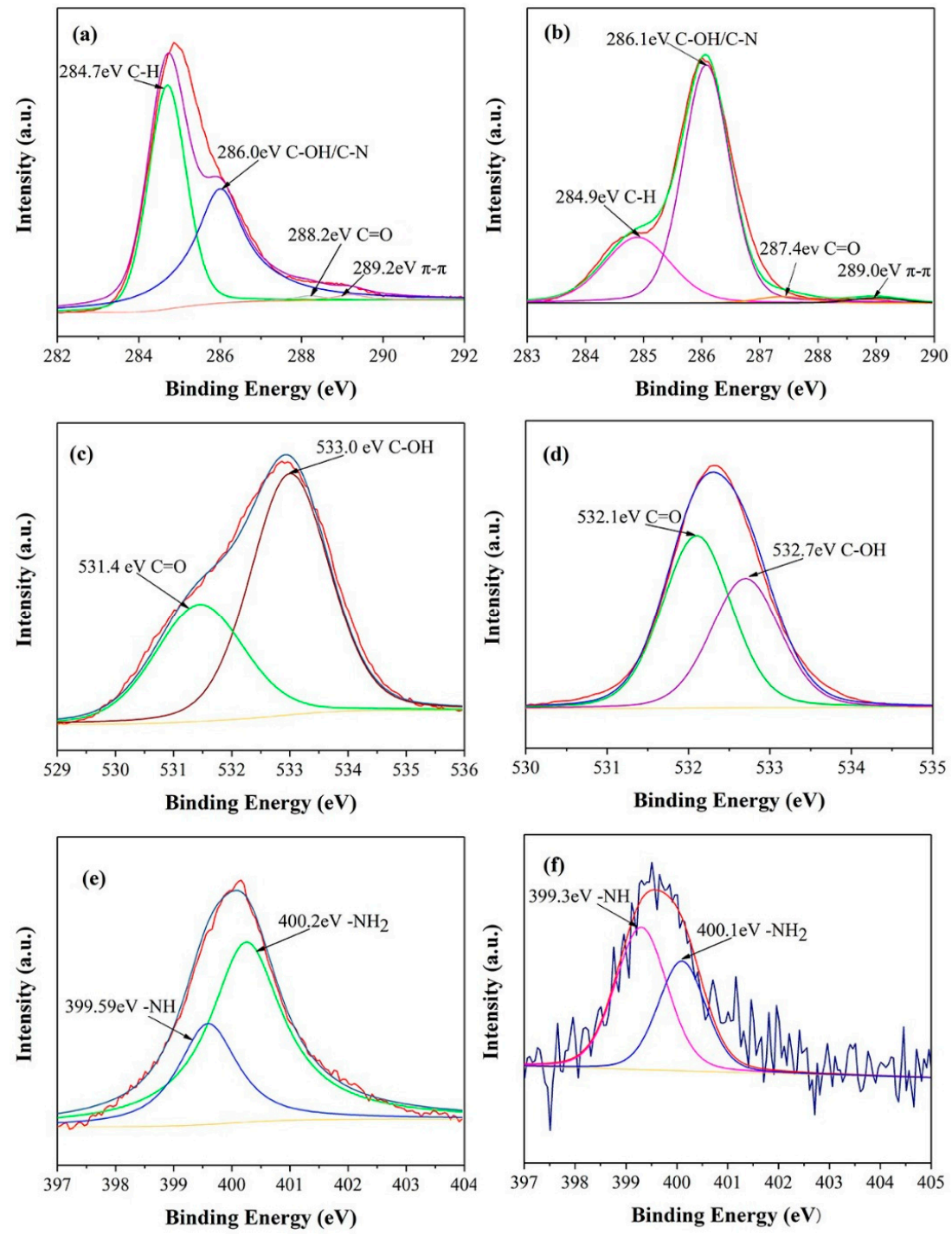

Figure 12. XPS patterns of the PDAMs: (a) C, (c) O, and (e) N, and XPS patterns of $75 \%$ PEG/PDAM-3: (b) C, (d) O, and (f) N. 


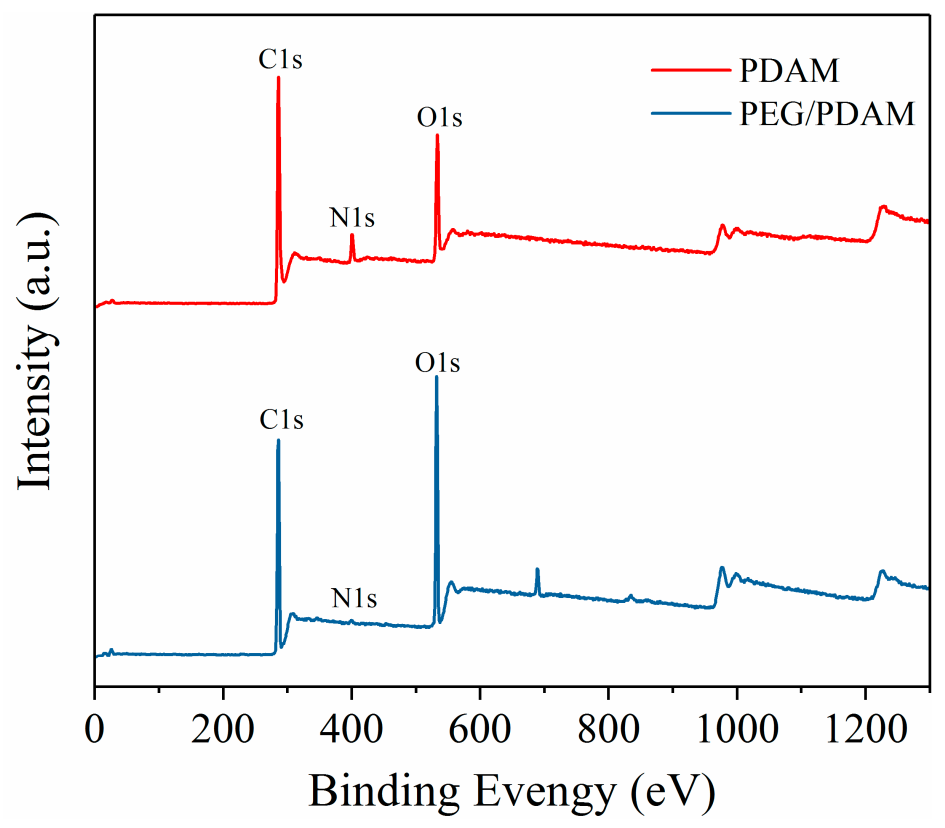

Figure 13. XPS survey of the PDAMs and PEG/PDAM-3.

\subsection{Comparison of PEG//PDAM-3 with Other Composite Materials}

The latent heat of PEG/PDAM-3 was compared with other form-stable phase change materials, which were also developed by physical adsorption through compounding PEG with supporting materials, and the results are shown in Table 2. It was clear that the thermal storage capacity of PEG/PDAM-3 was favourable and competitive, though the melting and freezing latent heats of PEG/PDAM-3 were not the highest. Moreover, PEG/PDAM-3 had excellent thermal stability and reliability, and the synthetic method of producing the PDAMs and PEG/PDAM-3 had a series of advantages, such as easy operation, mild conditions, and environmental friendliness. Therefore, PEG/PDAM-3 has the greatest potential in practical applications for thermal energy storage.

Table 2. Comparison of PEG/PDAM-3 with other composite materials.

\begin{tabular}{cccccc}
\hline \multirow{2}{*}{ Samples } & \multicolumn{2}{c}{ Melting } & \multicolumn{2}{c}{ Freezing } & \multirow{2}{*}{ References } \\
\cline { 2 - 5 } & $\mathbf{\Delta H m}(\mathbf{J} / \mathbf{g})$ & $\mathbf{T m}_{\mathbf{p}}\left({ }^{\circ} \mathbf{C}\right)$ & $\Delta \mathbf{H c}(\mathbf{J} / \mathbf{g})$ & $\mathbf{T c}_{\mathbf{p}}\left({ }^{\circ} \mathbf{C}\right)$ & \\
\hline PEG/PDAM-3 & $133.20 \pm 2.50$ & $62.20 \pm 0.00$ & $107.55 \pm 4.45$ & $31.10 \pm 0.60$ & Present study \\
PEG/AC ${ }^{a}$ & 81.30 & 49.00 & 72.80 & 27.80 & {$[48]$} \\
PEG/Dop-SF-3 ${ }^{b}$ & 73.80 & 53.00 & 69.10 & 44.80 & {$[43]$} \\
PEG/RMS & 129.60 & 57.22 & 118.30 & 39.02 & {$[49]$} \\
PEG/SiO $_{2}{ }^{d}$ & 151.80 & 58.09 & 141.00 & 42.34 & {$[10]$} \\
PEG/ZSM-5c & 76.40 & 60.50 & 64.30 & 44.90 & {$[35]$} \\
\hline
\end{tabular}

a PEG/AC: $80 \mathrm{wt} . \%$ of polyethylene glycol/active carbon. ${ }^{\mathrm{b}} \mathrm{PEG} /$ Dop-SF-3: $70 \mathrm{wt} . \%$ of polyethylene glycol/dopamine functionalized silica fume. ${ }^{c} \mathrm{PEG} / \mathrm{RMS}: 80 \mathrm{wt} . \%$ of polyethylene glycol/radial mesoporous silica. ${ }^{\mathrm{d}} \mathrm{PEG} / \mathrm{SiO}_{2}: 79.3$ wt.\% of polyethylene glycol/SiO $2 .{ }^{\text {e }} \mathrm{PEG} / \mathrm{ZSM}-5 \mathrm{c}$ : $50 \mathrm{wt} . \%$ of polyethylene glycol/mesoporous ZSM-5.

\section{Conclusions}

In this work, a novel high-efficient form-stable phase change material of PEG/PDAM was developed using a simple and environmentally friendly method. A series of tests, including SEM, TEM, XRD, DSC, XPS, BET, FTIR, and TGA, were carried out to study the properties of PEG/PDAMs. The results indicated that PEG adsorbed on the surface of PDAMs very well, and the interaction mechanisms between the PEG molecules and the PDAMs were hydrogen bonds linkages. The phase change property study results demonstrated that the PEG/PDAMs had high latent heat storage capacity, favourable thermal stability, and reliability, which enables it to have great potential in practical applications for thermal energy storage. Furthermore, because PDAMs have strong adsorption capacity 
for various organic materials, it can be used as a matrix for other organic materials in preparation of form-stable phase change materials.

Author Contributions: J.G., Z.C. and Y.C. conceived the research idea and designed the experiments. J.G., X.T., H.D., Y.L. and X.L. performed the experiments and analysed the data. J.G., X.T., Z.C. and Y.C. discussed the results and wrote the manuscript. All the authors reviewed the manuscript.

Acknowledgments: This research was funded by the financial support of the National Natural Science Foundation of China (Nos. 41776105 and 51606168), the Zhejiang Provincial Natural Science Foundation of China (No. LY18E060007) and the Science and Technology Planning Project of Zhoushan of China (No. 2018C21017).

Conflicts of Interest: There are no conflicts of interest to declare.

\section{References}

1. Chen, D.; Chen, Y.; Guo, X.W.; Tao, W.W.; Wang, J.B.; Gao, S.F.; Gao, J.K. Mesoporous silica nanoparticles with wrinkled structure as the matrix of myristic acid for the preparation of a promising new shape-stabilized phase change material via simple method. RSC Adv. 2018, 8, 34224-34231. [CrossRef]

2. Nguyen, T.T.T.; Park, J.S. Fabrication of Electrospun Nonwoven Mats of Polyvinylidene Fluoride/Polyethylene Glycol/Fumed Silica for Use as Energy Storage Materials. J. Appl. Polym. Sci. 2011, 121, 3596-3603. [CrossRef]

3. Konuklu, Y.; Ersoy, O. Preparation and characterization of sepiolite-based phase change material nanocomposites for thermal energy storage. Appl. Therm. Eng. 2016, 107, 575-582. [CrossRef]

4. Li, X.Y.; Chen, H.S.; Liu, L.; Lu, Z.Y.; Sanjayan, J.G.; Duan, W.H. Development of granular expanded perlite/paraffin phase change material composites and prevention of leakage. Sol. Energy 2016, 137, 179-188. [CrossRef]

5. Chen, J.J.; Ling, Z.Y.; Fang, X.M.; Zhang, Z.G. Experimental and numerical investigation of form-stable dodecane/hydrophobic fumed silica composite phase change materials for cold energy storage. Energy Convers. Manag. 2015, 105, 817-825. [CrossRef]

6. Wang, C.Y.; Wang, W.; Xin, G.B.; Li, G.L.; Zheng, J.; Tian, W.H.; Li, X.G. Phase change behaviors of PEG on modified graphene oxide mediated by surface functional groups. Eur. Polym. J. 2016, 74, 43-50. [CrossRef]

7. Shanmugana, S.; Palanib, S.; Janarthananc, B. Productivity enhancement of solar still by PCM and Nanoparticles miscellaneous basin absorbing materials. Desalination 2018, 433, 186-198. [CrossRef]

8. Pulci, G.; Paglia, L.; Genova, V.; Bartuli, C.; Valente, T.; Marra, F. Low density ablative materials modified by nanoparticles addition: Manufacturing and characterization. Compos. Part A Appl. Sci. Manuf. 2018, 109, 330-337. [CrossRef]

9. Akeiber, H.; Nejat, P.; Majid, M.; Abd, M.Z.; Wahid, M.A.; Jomehzadeh, F.; Famileh, I.Z.; Calautit, J.K.; Hughes, B.R. A review on phase change material (PCM) for sustainable passive cooling in building envelopes. Renew. Sustain. Energy Rev. 2016, 60, 1470-1497. [CrossRef]

10. Qian, T.T.; Li, J.H.; Ma, H.W.; Yang, J. The preparation of a green shape-stabilized composite phase change material of polyethylene glycol/ $/ \mathrm{SiO}_{2}$ with enhanced thermal performance based on oil shale ash via temperature-assisted sol-gel method. Sol. Energy Mater. Sol. Cells 2015, 132, 29-39. [CrossRef]

11. Veerakumar, C.; Sreekumar, A. Phase change material based cold thermal energy storage: Materials, techniques and applications-A review. Int. J. Refrig. 2016, 67, 271-289. [CrossRef]

12. Wang, J.J.; Yang, M.; Lu, Y.F.; Jin, Z.K.; Tan, L.; Gao, H.Y.; Fan, S.; Dong, W.J.; Wang, G. Surface functionalization engineering driven crystallization behavior of polyethylene glycol confined in mesoporous silica for shape-stabilized phase change materials. Nano Energy 2016, 19, 78-87. [CrossRef]

13. Cellata, K.; Beyhana, B.; Konuklub, Y.; Dundarc, C.; Karahand, O.; Gungore, C.; Paksoya, H. 2 years of monitoring results from passive solar energy storage in test cabins with phase change materials. Sol. Energy 2019. [CrossRef]

14. Su, W.G.; Darkwa, J; Kokogiannakis, G. Review of solid-liquid phase change materials and their encapsulation technologies. Renew. Sustain. Energy Rev. 2015, 48, 373-391. [CrossRef]

15. Liu, Y.R.; Xia, Y.P.; An, K.; Huang, C.W.; Cui, W.W.; Wei, S.; Ji, R.; Xu, F.; Zhang, H.Z.; Sun, L.X. Fabrication and characterization of novel meso-porous carbon/n-octadecane as form-stable phase change materials for enhancement of phase-change behavior. J. Mater. Sci. Technol. 2019, 35, 939-945. [CrossRef]

16. Li, M.; Guo, Q.G.; Nutt, S. Carbon nanotube/paraffin/montmorillonite composite phase change material for thermal energy storage. Sol. Energy 2017, 146, 1-7. [CrossRef] 
17. Ramakrishnan, S.; Wang, X.M.; Sanjayan, J.; Petinakis, E.; Wilson, J. Development of thermal energy storage cementitious composites (TESC) containing a novel paraffin/hydrophobic expanded perlite composite phase change material. Sol. Energy 2017, 158, 626-635. [CrossRef]

18. Zhang, Y.Z.; Zheng, S.L.; Zhu, S.Q.; Ma, J.N.; Sun, Z.M.; Farid, M. Evaluation of paraffin infiltrated in various porous silica matrices as shape stabilized phase change materials for thermal energy storage. Energy Convers. Manag. 2018, 171, 361-370. [CrossRef]

19. Lee, H.; Dellatore, S.M.; Miller, W.M.; Messersmith, P.B. Mussel-Inspired Surface Chemistry for Multifunctional Coatings. Science 2007, 318, 426-430. [CrossRef]

20. Zhang, Q.R.; Li, Y.X.; Yang, Q.G.; Chen, H.; Chen, X.Q.; Jiao, T.F.; Peng, Q.M. Distinguished Cr (VI) capture with rapid and superior capability using polydopamine microsphere: Behavior and mechanism. J. Hazard. Mater. 2018, 342, 732-740. [CrossRef]

21. Cheng, C.; Li, S.; Zhao, J.; Li, X.X.; Liu, Z.Y.; Ma, L.; Zhang, X.; Sun, S.D.; Zhao, C.S. Biomimetic assembly of polydopamine-layer on graphene: Mechanisms, versatile 2D and 3D architectures and pollutant disposal. Chem. Eng. J. 2013, 228, 468-481. [CrossRef]

22. Zhu, Y.; Chi, Y.; Liang, S.; Luo, X.; Chen, K.; Tian, C.; Wang, J.; Zhang, L. Novel metal coated nanoencapsulated phase change materials with high thermal conductivity for thermal energy storage. Sol. Energy Mater. Sol. Cells 2018, 176, 212-221. [CrossRef]

23. Li, H.; Jia, Y.; Peng, H.N.; Li, J.B. Recent developments in dopamine-based materials for cancer diagnosis and therapy. Adv. Colloid Interface Sci. 2018, 252, 1-20. [CrossRef] [PubMed]

24. Bai, L.F.; Duan, S.X.; Jiang, W.Q.; Liu, M.; Wang, S.; Sang, M.; Gong, X.L.; Li, J.X.; Xuan, S.H. High performance polydopamine-functionalized mesoporous silica nanospheres for U(VI) removal. Appl. Surf. Sci. 2017, 426, 1121-1132. [CrossRef]

25. Khalil, F.; Neda, F. Polydopamine nanoparticles as a new nanobiopolymer for the biosorption of L-cysteine from aqueous solutions. J. Iran. Chem. Soc. 2015, 12, 347-357.

26. Hong, Y.; Wu, W.; Hu, J.J.; Zhang, M.H.; Voevodin, A.A.; Chow, L.; Su, M. Controlling supercooling of encapsulated phase change nanoparticles for enhanced heat transfer. Chem. Phys. Lett. 2011, 504, 180-184. [CrossRef]

27. Wang, Y.; Zhang, Y.; Xia, T.D.; Zhao, W.J.; Yang, W.H. Effects of fabricated technology on particle size distribution and thermal properties of stearic-eicosanoic acid/polymethylmethacrylate nanocapsules. Sol. Energy Mat. Sol. Cells 2014, 120, 481-490. [CrossRef]

28. Zhao, Y.J.; Min, X.; Huang, Z.H.; Liu, Y.G.; Wu, X.W.; Fang, M.H. Honeycomb-like structured biological porous carbon encapsulating PEG: A shape-stable phase change material with enhanced thermal conductivity for thermal energy storage. Energy Build. 2018, 158, 1049-1062. [CrossRef]

29. Kou, Y.; Wang, S.Y.; Luo, J.P.; Sun, K.Y.; Zhang, J.; Tan, Z.C.; Shi, Q. Thermal analysis and heat capacity study of polyethylene glycol (PEG) phase change materials for thermal energy storage applications. J. Chem. Thermodyn. 2019, 128, 259-274. [CrossRef]

30. Meng, M.J.; Meng, X.G.; Liu, Y.; Liu, Z.C.; Han, J.; Wang, Y.; Luo, M.; Chen, R.; Ni, L.; Yan, Y.S. An ion-imprinted functionalized SBA-15 adsorbent synthesized by surface imprinting technique via reversible addition-fragmentation chain transfer polymerization for selective removal of Ce (III) from aqueous solution. J. Hazard. Mater. 2014, 278, 134-143. [CrossRef]

31. Golitsyna, Y.; Pulstb, M.; Samiullahb, M.H.; Busseb, K.; Kresslerb, J.; Reicherta, D. Crystallization in PEG networks: The importance of network topology and chain tilt in crystals. Polymer 2019, 165, 72-82. [CrossRef]

32. Wang, C.Y.; Feng, L.L.; Li, W.; Zheng, J.; Tian, W.H.; Li, X.G. Shape-stabilized phase change materials based on polyethylene glycol/porous carbon composite: The influence of the pore structure of the carbon materials. Sol. Energy Mat. Sol. Cells 2012, 105, 21-26. [CrossRef]

33. Sar1, A.; Bicer, A.; Al-Sulaiman, F.A.; Karaipekli, A.; Tyagi, V.V. Diatomite/CNTs/PEG composite PCMs with shape-stabilized and improved thermal conductivity: Preparation and thermal energy storage properties. Energy Build. 2018, 164, 166-175. [CrossRef]

34. Deng, Y.; Li, J.H.; Qian, T.T.; Guan, W.M.; Li, Y.L.; Yin, X.P. Thermal conductivity enhancement of polyethylene glycol/expanded vermiculite shape-stabilized composite phase change materials with silver nanowire for thermal energy storage. Chem. Eng. J. 2016, 295, 427-443. [CrossRef]

35. Li, C.E.; Yu, H.; Song, Y.; Zhao, M. Synthesis and characterization of PEG/ZSM-5 composite phase change materials for latent heat storage. Renew. Energy 2018, 121, 45-52. [CrossRef] 
36. Zhang, X.G.; Wen, R.L.; Tang, C.; Wu, B.G.; Huang, Z.H.; Min, X.; Huang, Y.T.; Liu, Y.G.; Fang, M.H.; Wu, X.W. Thermal conductivity enhancement of polyethylene glycol/expanded perlite with carbon layer for heat storage application. Energy Build. 2016, 130, 113-121. [CrossRef]

37. Liu, X.S.; Gao, J.M.; Li, H.; Li, J.Y.; Jin, Q.; Ren, K.F.; Ji, J. Mussel-Inspired Polydopamine: A biocompatible and ultrastable coating for nanoparticles in vivo. ACS Nano 2013, 7, 9384-9395. [CrossRef] [PubMed]

38. Dreyer, D.R.; Miller, D.J.; Freeman, B.D.; Paul, D.R.; Bielawski, C.W. Elucidating the Structure of Poly(dopamine). Langmuir 2012, 28, 6428-6435. [CrossRef] [PubMed]

39. Rudner, M.S.; Jeremic, S.; Petterson, K.A.; Kent, D.R.; Brown, K.A.; Drake, M.D.; Goddard, W.A.; Roberts, J.D. Intramolecular Hydrogen Bonding in Disubstituted Ethanes. A Comparison of $\mathrm{NH} \ldots \mathrm{O}-$ and $\mathrm{OH} \ldots$ O- Hydrogen Bonding through Conformational Analysis of 4-Amino-4-oxobutanoate (succinamate) and Monohydrogen 1,4-Butanoate (monohydrogen succinate) Anions. J. Phys. Chem. A. 2015, 109, 9076-9082. [CrossRef]

40. Hong, S.; Na, Y.S.; Choi, S.; Song, I.T.; Kim, W.Y.; Lee, H. Non-Covalent Self-Assembly and Covalent Polymerization Co-Contribute to Polydopamine Formation. Adv. Funct. Mater. 2012, 22, 4711-4717. [CrossRef]

41. Vecchia, N.F.D.; Avolio, R.; Alfè, M.; Errico, M.E.; Napolitano, A.; D’Ischia, M. Building-Block Diversity in Polydopamine Underpins a Multifunctional Eumelanin-Type Platform Tunable Through a Quinone Control Point. Adv. Funct. Mater. 2013, 23, 1331-1340. [CrossRef]

42. Iuczak, T. Preparation and characterization of the dopamine film electrochemically deposited on a gold template and its applications for dopamine sensing in aqueous solution. Electrochim. Acta 2008, 53, 5725-5731.

43. Chen, Y.; Ding, H.; Wang, B.F.; Shi, Q.; Gao, J.K.; Cui, Z.X.; Wan, Y.C. Dopamine functionalization for improving crystallization behavior of polyethylene glycol in shape-stable phase change material with silica fume as the matrix. J. Clean. Prod. 2019, 208, 951-959. [CrossRef]

44. Clark, M.B.; Gardella, J.A.; Schultz, T.M.; Patil, D.G.; Salvati, L. Solid-state Analysis of Eumelanin Biopolymers by Electron Spectroscopy for Chemical Analysis. Anal. Chem. 1990, 62, 949-956. [CrossRef]

45. Kaminska, I.; Das, M.R.; Coffinier, Y.; Jonsson, J.N.; Sobczak, J.; Woisel, P.; Lyskawa, J.; Opallo, M.; Boukherroub, R.; Szunerits, S. Reduction and Functionalization of Graphene Oxide Sheets Using Biomimetic Dopamine Derivatives in One Step. ACS Appl. Mater. Interfaces 2012, 4, 1016-1020. [CrossRef]

46. Xi, Z.Y.; Xu, Y.Y.; Zhu, L.P.; Wang, Y.; Zhu, B.K. A facile method of surface modification for hydrophobic polymer membranes based on the adhesive behavior of poly (DOPA) and poly(dopamine). J. Membr. Sci. 2009, 327, 244-253. [CrossRef]

47. Mackie, N.M.; Castner, D.G.; Fisher, E.R. Characterization of Pulsed-Plasma-Polymerized Aromatic Films. Langmuir 1998, 14, 1227-1235. [CrossRef]

48. Feng, L.L.; Zhao, W.; Zheng, J.; Frisco, S.; Song, P.; Li, X.G. The shape-stabilized phase change materials composed of polyethylene glycol and various mesoporous matrices (AC, SBA-15 and MCM-41). Sol. Energy Mat. Sol. Cells 2011, 95, 3550-3556. [CrossRef]

49. Min, X.; Fang, M.H.; Huang, Z.H.; Liu, Y.G.; Huang, Y.T.; Wen, R.L.; Qian, T.T.; Wu, X.W. Enhanced thermal properties of novel shape-stabilized PEG composite phase change materials with radial mesoporous silica sphere for thermal energy storage. Sci. Rep. 2015, 5, 12964. [CrossRef]

(C) 2019 by the authors. Licensee MDPI, Basel, Switzerland. This article is an open access article distributed under the terms and conditions of the Creative Commons Attribution (CC BY) license (http://creativecommons.org/licenses/by/4.0/). 